\title{
Efficiency in Solar Photovoltaic Systems Under High Temperature Conditions
}

\author{
Nuru Safarov ${ }^{1,}$, , Sevinc Orucova ${ }^{2}$, Gurban Ahmadov $^{3}$, Etibar Rzazadeh ${ }^{4}$, Samira Cafarova $^{4}$ \\ ${ }^{1}$ Department of Electronics and Telecommunications Engineering, Khazar University, Baku, Azerbaijan \\ ${ }^{2}$ Department of Medical Physics and Informatics, Azerbaijan Medical University, Baku, Azerbaijan \\ ${ }^{3}$ Laboratory of Heterostructures Physics, Institute of Physics of Azerbaijan National Academy of Sciences, Baku, Azerbaijan \\ ${ }^{4}$ Educational Technopark, Odlar Yurdu University, Baku, Azerbaijan
}

Email address:

nsafarov@khazar.org(N. Safarov)

${ }^{*}$ Corresponding author

\section{To cite this article:}

Nuru Safarov, Sevinc Orucova, Gurban Ahmadov, Etibar Rzazadeh, Samira Cafarova. Efficiency in Solar Photovoltaic Systems Under High Temperature Conditions. International Journal of Electrical Components and Energy Conversion. Vol. 3, No. 6, 2017 , pp. 88-92. doi: 10.11648/j.ijecec.20170306.11

Received: December 26, 2017; Accepted: January 10, 2018; Published: January 22, 2018

\begin{abstract}
Alternative energy sources already today can satisfy human needs for energy. A spectrum of natural sources different from region to region. Intensity sunlight and a wind, existence or absence of water energy, geothermal sources, wood potential, quality soil and quantity of dropping out deposits for cultivation of a biomass influence a choice of that combination in which kinds of renewed energy in this or that country will be combined. From here follows, which energy needs in various regions should be satisfied with various ways.
\end{abstract}

Keywords: Solar Energy, Concentrator, Power Factor, Photovoltaic Cells, Temperature, Converter

\section{Introduction}

Mineral kinds of energy by the nature are diverse and multipurpose, but also in it essentially lag solar sources. The wide spectrum of a sunlight allows to carry out selective use of waves various lengths for the various purposes: ultraviolet radiations, for example, for disinfecting potable water, light of a seen range for reception of an electric current, and use of a long-wave infra-red part of a spectrum for reception of heat. Have been given information for increasing the efficiency of the photovoltaic devices about efficiency of the application sun thermodynamic pursue in the article. Construction solution have been analyzed thermodynamic pursue. The overage annual amount of solar energy, penetrating to a constant area of the Earth's surface within an hour, varies between the figures $7,2-21,4 \mathrm{MJ} / \mathrm{m}^{2}$. During the year, $5.6 \times 10^{24} \mathrm{~J}$ of solar energy falls on the upper boundary of the earth's surface. Earth's Atmosphere reflects $35 \%$ in space and the rest is spent on heating the earth's surface, evaporation - precipitation, the formation of waves in the seas and oceans, air and ocean currents. For example, as solar devices sources of ecologically, clean autonomous energy which are used for charging batteries, lighting, power supply for $\mathrm{TV}$, video and audio equipment, power supply for telecommunication, residential properties can be shown.

Energy transformation in photocells with a concentrator is based on the action of solar rays, semiconductors with a nonprimary structure, referring to the photovoltaic effect. The power of concentrating photo galvanic cells can be used as energy of food sources. In comparison with other sources, their operating mode depends on the intensity of solar rays. Concentrated solar radiation power systems can be used in various forms depending on the electrical or high temperature energy conversion. However, in our time, these systems are mainly focused on the acquisition of the electric current [1-4].

\section{Materials and Methods}

The standards required during the testing of elements and generally accepted throughout the world are as follows: lighting $1000 \mathrm{~kW} / \mathrm{m}^{2}$, temperature $25^{\circ} \mathrm{C}$ and $A M 1.5$ (mass of 
atmosphere the solar spectrum in a circle of $45^{\circ}$ ). The main energy properties of solar cells used in photo galvanic devices are measured according to the scheme shown in the figure. Short -circuit current, open circuit voltage, the coefficient of filling of photocells etc., can be shown as an example of these measured parameters.

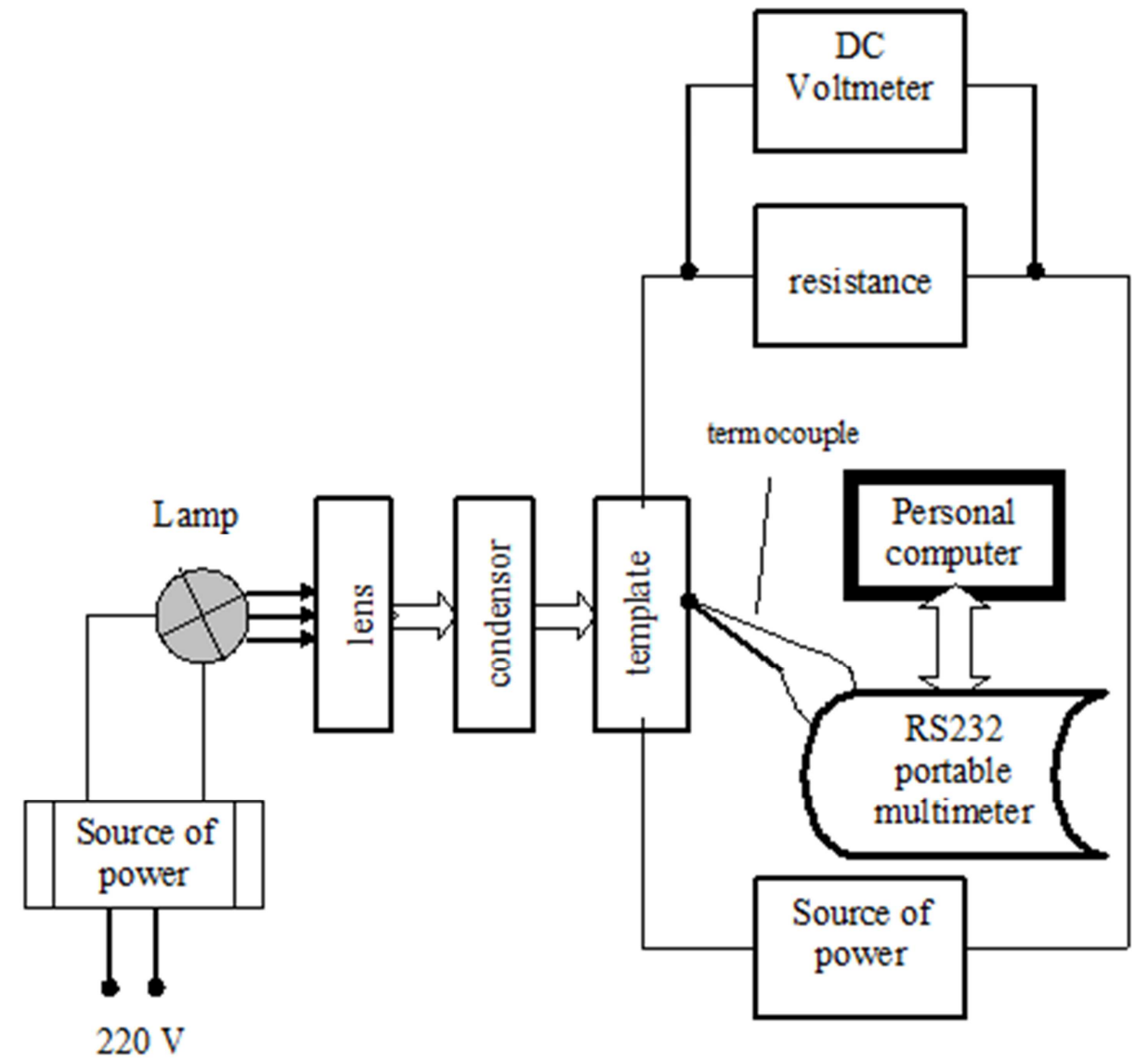

Figure 1. Scheme of electrical parameters of photovoltaic objects.

Although it is easy to obtain solar energy, - its concentration is relatively weak. For this reason, collecting energy with the help of light collectors, which cost is low, profitable. This situation allows solar energy to complete with traditional energy sources [5-8]. The shortage of solar radiation as a source of energy is its uneven penetration to the earth's surface depending on its daily cycle and seasonal changes, as well as weather conditions. For this reason, the problem of accumulating electricity produced by solar units is very important. At present, this problem is mainly solved by using conventional chemical accumulators. One of the most promising methods of collecting energy is the use of electricity for the electrolysis of oxygen and hydrogen, subsequently.

The low density of a falling solar energy does not allow using effectively directly the turned-out technologies of photo-electric transformation of a solar energy in electricity. Really, even the most perfect photo-electric solar modules from efficiency of transformation of $15-18 \%$, being the buildings established motionlessly on a roof and orientated in a direction on the South, can develop within day only $2 / 3$ face values for two obvious reasons [9-12]:

1. Low sunlight, not exceeding $600-800 \mathrm{~W} / \mathrm{m}^{2}$, instead of nominal $1000 \mathrm{~W} / \mathrm{m}^{2}$ on which the solar module pays off.
2. The influence of "cosine - factor" connected to daily movement of the Sun on a sky because of which the maximum of developed energy is necessary only for a while, close to midday when the accepting surface of the photo-electric module is focused precisely on the Sun.

To correct position with low density of a falling solar energy use of concentrators of sunlight can. The sense of use of concentrators is made in that with the help of simple lenses in the form of a prism is artificial to increase density of sunlight and by that to receive that quantity of the produced electricity for which the module is designed. Naturally such completion will demand also necessity to focus accepting surface of the photo-electric module supplied with concentrators, in a direction on the Sun. Only in this case the concentrator - the assistant, and without observation daily movement of the Sun on a sky use of the concentrator not only is unjustified, but even harmful. At the same time, constantly focusing the photo-electric module with the concentrator on the Sun, we get rid of influence above mentioned "cosine - factor". Thus, use in photo-electric installation of concentrators of a sunlight and daily observation the Sun allows to increase much more daily quantity of developed electric energy. 
Certainly, such installation will cost essentially more expensively, than the solar photo-electric installation made of motionlessly fixed solar photo-electric modules, due to application of a complex design of the rotary mechanism with system of automatic observation the Sun. However, expenses for purchase of such installation can soon be paid back for the account more its high daily energy production $[13,14]$.

Besides solar photo-electric installations with concentrators can be used for the combined manufacture, both electric, and thermal energy collecting on the photo panel the seen part of a sunlight and passing infra-red part of a spectrum on thermal collectors, installed under photo cells.
Suggested installation will structurally consist of the twoaxial supporting-rotary device (1), the frame - basis of a design (2) with the photo-electric modules fixed on it with peak capacity of the developed electric power $40 \mathrm{~W}$, a photodetector - the converter (3) made of a set of elements from monocrystal silicon, connected consistently, available along an axis of the concentrator (4) and forming the photobattery. The concentrator of the energetically installations, represents prisms focus $25 \mathrm{~cm}$, made of 2 parts of the rectangular form with the active area $2 \times 20 \mathrm{~cm} \times 40 \mathrm{~cm}=1600 \mathrm{~cm}^{2}$.

The principle of work of the device is illustrated by figure.

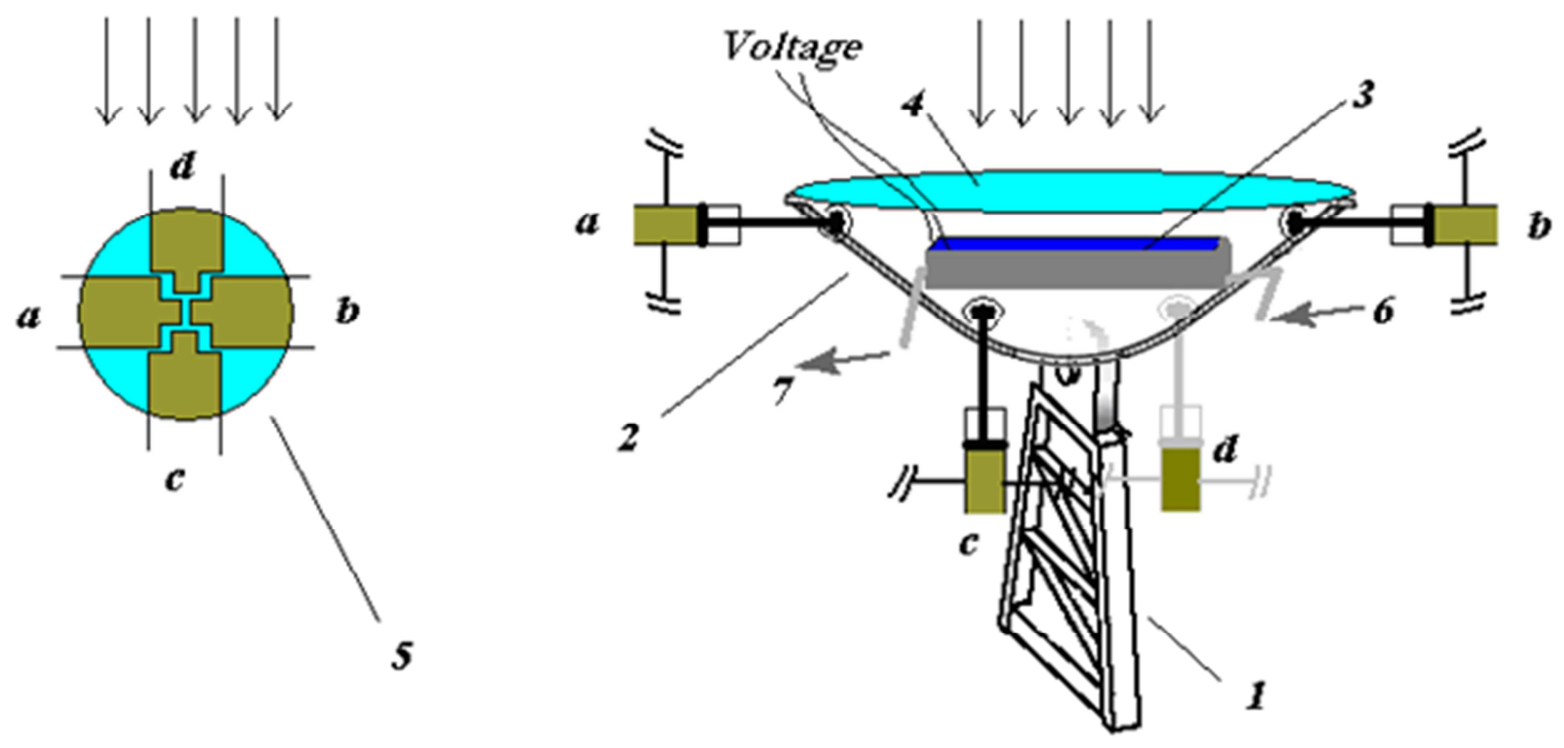

Figure 2. Photoelectric installation with thermodynamic observation.

The concentrator provides uniform light exposure of all elements of a photodetector and increases his light exposure at 10-12 times. Rotation of the supporting - rotary device is carried out around of a vertical and horizontal axis by system of watching drives with thermodynamic positions of the Sun (5), cylinders which are placed frame - bas the supporting rotary device $(a, b, c, d)$.

\section{Results and Discussion}

Improvement of factor of transformation of a solar energy in electric is provided with cooling of a photo cell with the help of water, by natural convection. Allocated during work warmly from an output of a radiator of a photodetector as warming up to $30-40^{\circ} \mathrm{C}$ waters acts on the water-heating element executed in the form of a pipe, installed in focus of the concentrator, available behind an element from which output the temperature of water can reach up to $80^{\circ} \mathrm{C}(6,7)$.

Thus, electric energy of a direct current is removed from an output of installation with face value of voltage $4.5 \mathrm{~V}$ and a total current $9 \mathrm{~A}$.

Materials used and in the solar module with concentration and their cost, at the area $1 \mathrm{~m}^{2}$.
Table 1. Materials used and in the solar module with concentration and their cost, at the area $1 \mathrm{~m}^{2}$.

\begin{tabular}{llll}
\hline Material & Element of a design & Lump, kg & Cost, \$ \\
\hline Aluminum & Radiator & 4 & 28 \\
Polymer & Lens and the case & 15 & 32 \\
Steel & $\begin{array}{l}\text { Rotating system and system of } \\
\text { Shadowing }\end{array}$ & 12 & 10 \\
Concrete & The basis & 20 & 4 \\
\hline
\end{tabular}

Before comparing different energy technologies, it is necessary to determine their true value. Only the approval of normal prices will create incentives aimed at creating new technologies in the energy sector. In many reports it isn't consider the inconsistencies of the maxim point when feeding in the inventory, which converts the current into a current, with the loss of rotation of the module, with the current voltage characteristics of the actual load.

The current level of production of solar cells is at the initial stage of their use. Their price is $2,5-3 \$ / W$. Solar energy systems replace kerosene lamp, cells and batteries, diesel generators and power lines. The second phase of mass production of solar cells and its connection to the overall energy system, reducing the cost of production by 5 times, is associated with the creation of materials and technologies 
reaching up to $1 \$ / W$. This reduction is mainly limited to the high cost of silica used for this purpose $-40-100 \$$. 35 years ago, prepared and obtained by the technology of silicone dioxide, containing all the negative features of chemical terminology practically didn't change. Silica which is the main material in the production of silicon is $12 \%$ of the lithospheric mass. Connection that has a high energy requires the use of a reaction and its subsequent purification by chemical methods - $250 K W^{*} h o u r / k q$. While the yield of silicon is $6-10 \%$. In addition to silicon for the photovoltaic industry, a special glass with a small presence of iron, aluminum rolling's, electronic cleaners are necessary.

Because $1 \mathrm{~kg}$ of the solar cell of silicon produces about $300 \mathrm{MW}$ of electric power for 30 years, the oil equivalent of silicon can be easily calculated. Taking into account the fact that the temperature of burning oil is $437 \mathrm{MJ} / \mathrm{kg}$, we can assume that $1 \mathrm{~kg}$ of silicon corresponds to 25Tonne of oil. If we consider the fact that efficiency of power stations, working on full oil is $33 \%$, in this case this equivalent is 75Tonne. Due to the fact that solar station are already being used in practice, it is possible to conduct a detailed economic analysis, basing on prices, set by enterprises polymer material, radiators made of aluminum, tracking system, made of steel and support elements of construction made of concrete base are used [3].

Solar fluorescent lights have a better performance than conventional flat designs. It is important that aluminum radiators which make up about half of the consumed energy, are strong and it is necessary to consider the repeated use of radiators during the replacement of the lens or elements. The need to reduce the service life according to the cost raises such urgent problems as development of more efficient solar cells, possessing stations designs more efficient economic indicators. Solar energy can be converted into thermal, mechanical and electrical energy, and can be used in chemical and biological processes. Solar technologies have found their application in heating systems, cooling of residential buildings, technological processes at low and high temperatures [6]. Dry and semi-desert zones in Azerbaijan are very suitable for the location of solar power stations. From this point of view, the development of solar energy in our republic is perspective.

The concentrating power systems of the solar system can be used in such forms as electric or high - temperature power generation. However, in the modern era, these systems are mainly focused on the acquisition of electric current. The areas of use of various types of solar capacitor system are extensive. Concentrates of parabolic forms have found their best application in solving such processes as low-temperature detoxification, warming of liquids and their circulation. All systems are designed for use at moderate temperatures. The tower system is best suited for temperatures above $1000^{\circ} \mathrm{C}$ [1].

The technology of wide use of electric and high temperature production is unstable, and investment of capital is high in comparison with current energy sources such as natural gas. However, wide range of usage and low emissions of $\mathrm{CO}_{2}$ gives him great advantages. In the product of electric current photovoltaic system are connected to operating devices using an inverter. Inverters are electronic devices that connect photoelectric devices directly with consumers of energy and thus, convertor the direct current into an alternating current demanded by consumers. In addition to achieving high efficiency and maximum conversion power in converting inverters must create an alternating current with the required quality. Inverters must also be safe for control devices and directly for employees using it. The direct current power at the input of the invertor depends on the point of use of the curve of the power characteristic of the volt-ampere of the photovoltaic system. Ideally, the inverters should be placed at the maximum power point of the photovoltaic system. The maximum power point changes throughout the day and in fact an environmental factor and a function of temperature. But the invertors, directly related to the photovoltaic system have the greatest efficiency of power tracking.

The maximum power tracking ratio can be defined as:

$$
\eta=\frac{\int_{0}^{t} P_{D C} d t}{\int_{0}^{t} P_{m} d t}
$$

Here the power of the direct current transmitted to the invertor corresponds to the maximum power point.

\section{Conclusions}

The algorithms of the coefficient of many maximum power points are justified differently based on many parameters. After specific temporary changes in the photovoltaic system such algorithms are adjusted based on minor $\Delta V$ changes in working tension because of a change in the measured power. If $\Delta P$ is positive, then the corresponding increasing voltage is also positive; if $\Delta P$ is negative, then the subsequent change in voltage is negative. However, this algorithm has some limitations and reduces the efficient of the maximum power factor during operation. During a low radiation level, for example, at Sunrise and Sunset, the power curve is flat, and this position leads to a difficult determination of the location of the present power point. Another factor - since the invertor dances with $\Delta P$ around the maximum power point, in this case it is more difficult to determine the exact location of this point. The monitoring algorithm may show incorrect behavior with rapidly changing radiation. Finding certain parts of the system under the shadow also affects the maximum power point, but this problem can be solved as a function of time as a function of change in power at a selective time.

As a result, it can be concluded, the application area of different types of solar concentrator system are also wide. Concentrators of parabolic shape can find the best application in detoxification at a low temperature range of heating liquids and their solution during circulation. All systems are useful for applying them in practice at medium temperature. 
The tower system is most favorable for obtaining a temperature above $1000^{\circ} \mathrm{C}$.

\section{References}

[1] R. S. Madatov, A. M. Hashimov, N. A. Safarov, G. M. Ahmadov. Calculation method and results of electricity production by solar photoelectrical devices for the Azerbaijan climatic zones. Power Engineering Problems, 2003 v. 20 (6); pp. 6.

[2] N. A. Safarov, F. N. Tatardar, S. S. Amirov. The Hybride Composites Based New Materials for the Electromechanical and Acoustico-Electrical Converters. Journal of Non-Oxide Glasses. 2017, Vol 9 (1), pp. 19-23.

[3] N. Safarov, G. Axmedov, S. Axmedov. Investigations of Mathematical Models in Solar Collectors. American Journal of Energy Engineering, 2014, Volume2, Issue3, pp. 75-79.

[4] Nuru Safarov. Polymer - Silicon Sensor for Determination Flow. Global Journal of Engineering Science and Research Management. 3 (9): September 2016, vol. 3, no. 9, pp. 19-21.

[5] A. A. Bayramov, N. A. Safarov. Automatic Photoelectric Device for Most Optimum Illumination of Objects, ICCES International Conference on Computational \& Experimental Engineering and Sciences, 2008, vol. 5, no. 3, pp. 173-178.

[6] A. A. Bayramov, A. M. Hashimov, N. A. Safarov, F. J. Safarova. A solar power plant with a high performance solar cells and thin concentrators made of aluminumbacked epoxy coated polymers. - Proc. TPE-2006, 2006, pp. 29-31.
[7] G Abdullaev, M Bakirov, N Safarov. Silicon solar cells with antireflection layers of silicon oxide and nitride. Applied solar energy, Volume 29. Issue 1. pages 76-78. 1993.

[8] F. G. Aliev, E. M. Rzazadeh, N. A. Safarov, I. Q. Aliev, N. N. Mursakulov. Basic construction for solar power plants. 10-th Baku Intern. Congress "Energy, Ecology, Economy", 23-25 September, Baku, 2009, pp. 93-96.

[9] F. G. Aliev, N. A. Safarov, E. M. Rzazadeh. Computer network, gathering and analysis of ecoenergetic parameters of Azerbaijan Republic. Eighth Baku International Congress "Energy, Ecology, Economy" 1-3 June 2005 - Baku, Azerbaijan, pp. 202-206.

[10] E. M. Rzazadeh. N. A. Safarov. Monitoring of intensity of electromagnetic radiation. $3^{\text {nd }}$ Inter. Conference on Technical and Physical Problems in Power Engineering, May 29-31, 2006 Ankara, Turkey, pp. 687-689.

[11] AA Bayramov, AM Hashimov, NA Safarov, GM Akhmedov. Thermophotovoltaic Solar Energy Converters on the Basis AVBVI. 2006 IEEE 4th World Conference on Photovoltaic Energy Conference. Volume 1. 2006/5, pp. 651-654.

[12] R. Singh. Economic requirements for new materials for solar photovoltaic cells/ Solar Energy. 1980, v. 24, №6, p. 589-592.

[13] Werner, J. H., Mattheis, J., and Rau, U. (2005) Efficiency limitations of polycrystalline thin film solar cells: case of $\mathrm{Cu}$ (In, Ga) Se2. Thin Solid Films, 480/481, 399-409.

[14] R. Swanson, S. Beckwith, R. Crane, W. Eades et all. / Point Contact Concentration Solar Cells - IEEE Electron Devices Letters, Vol. ED-31, No5, May 1984, pp. 661-664. 